\title{
The art of shockwave lithotripsy is an endangered species and is worth saving: the perspective of the European Association of Urology (EAU) Young Academic Urology (YAU) Urolithiasis group
}

\author{
Patrick Juliebø-Jones ${ }^{1,2}$ (1) Etienne Xavier Keller ${ }^{3} \cdot$ Thomas Tailly $^{4} \cdot$ Mathias Sørstrand Æsøy $^{1} \cdot$ Francesco Esperto $^{5}$. \\ loannis Mykoniatis ${ }^{6} \cdot$ Vincent de Coninck $^{7}$. Amelia Pietropaolo ${ }^{8}$
}

Received: 1 November 2021 / Accepted: 3 November 2021 / Published online: 17 November 2021

(c) The Author(s), under exclusive licence to Springer-Verlag GmbH Germany, part of Springer Nature 2021

Keywords Ureterorenoscopy · Urolithiasis · Extracorporeal shock wave lithotripsy · Education

\section{Dear Editor,}

We read with great interest the recent study by Herout et al., which shines a spotlight on the current status of shockwave lithotripsy (SWL) in Germany [1]. The findings confirm the rise of ureteroscopy (URS) and fall of SWL as the endourological treatment of choice for urolithiasis. The results mirror those from many other countries including the United Kingdom and United States [2]. To this end, it seems fair, therefore, that Herout et al. chose the word 'extinction' in their title [1]. However, perhaps this particular report on SWL's decline, is even more thought provoking given that

This comment refers to the article available online at https://doi. org/10.1007/s00345-021-03818-y.

Patrick Juliebø-Jones

jonesurology@gmail.com

1 Department of Urology, Haukeland University Hospital, Bergen, Norway

2 Department of Clinical Medicine, University of Bergen, Bergen, Norway

3 Department of Urology, University Hospital Zurich, University of Zurich, Zurich, Switzerland

4 Department of Urology, University Hospitals Ghent, Ghent, Belgium

5 Department of Urology, University of Rome, Campus Bio-medico, Rome, Italy

6 Department of Urology, School of Medicine, Faculty of Health Sciences, Aristotle University of Thessaloniki, Thessaloniki, Greece

7 Department of Urology, AZ Klina, Brasschaat, Belgium

8 Department of Urology, University Hospital Southampton, Southampton, UK it hails from the very country where the technology was first pioneered in the 1980s. For SWL, these results may, therefore, feel somewhat like an eviction notice placed on its front door.

While SWL has undergone modifications since its early 'bathtub' days in the 1980s, the constant advancements in URS are unremitting and show no signs of slowing down. The emergence of light amplification by stimulated emission of radiation (laser) for use in intra-corporeal lithotripsy as well as the development of fiberoptic and digital ureteroscopes have certainly played a key role in this [3]. Concepts such as Moses technology and more recently, Thulium fiber laser (TFL) have fueled this even further [4, 5]. Indeed, URS is the proverbial candy store all residents want to visit. Even in paediatric urolithiasis, SWL has been brought into question given the high efficacy of URS [6].

If "we are what we eat", then perhaps for residents SWL is poorly represented on the menus of academic conferences. While we are not necessarily calling for the dish of the day to be 'Live SWL sessions', it should feature more than just as a side order.

The recent multicentre randomised controlled non-inferiority trial comparing Shockwave Lithotripsy Versus Ureteroscopic Treatment as Therapeutic Interventions for Stones of the Ureter (TISU) has re-awoken the urology community to the possible merits of SWL [7]. However, for its benefits to be maximised, patient selection is crucial. So too is the investment in time for training. Okada et al. improved their overall success rate with SWL by over $20 \%$ with additional training [8]. High frequency of cases by individual operators $(>150)$ has also been shown to deliver better outcomes [9]. During the COVID-19 pandemic, SWL also demonstrated its value in centres where operating theatres were not available to use [10]. It can also play a role in patients 
with multiple comorbidities where the anaesthetic risk may be high. We must, therefore, strive to not select treatment choices be dictated by the procedure we enjoy the most.

The role of SWL in urology is diminishing and the study by Herout et al. confirms this. However, we argue that it is not SWL itself that is facing extinction but rather, the art of delivering the service well. The story of SWL is not over yet and there is still time to change the narrative.

Acknowledgements PJ wishes to thank Øyvind Ulvik, Christian Beisland, and Bhaskar Somani for their expertise and guidance in formulating debate on this this topic.

\section{Funding Nil.}

\section{Declarations}

Conflict of interest None to be declared by any of the authors.

Research involving human participants and/or animals Not applicable.

Informed consent Not applicable.

\section{References}

1. Herout R, Baunacke M, Groeben C, Aksoy C, Volkmer B, Schmidt M, Eisenmenger N, Koch R, Oehlschläger S, Thomas C, Huber J (2021) Contemporary treatment trends for upper urinary tract stones in a total population analysis in Germany from, 2006 to 2019: will shock wave lithotripsy become extinct? World J Urol. https://doi.org/10.1007/s00345-021-03818-y

2. Geraghty RM, Jones P, Somani BK (2017) Worldwide trends of urinary stone disease treatment over the last two decades: a systematic review. J Endourol 31(6):547-556. https://doi.org/10. 1089/end.2016.0895 (PMID: 28095709)

3. Keller EX, De Coninck V, Traxer O (2019) Next-generation fiberoptic and digital ureteroscopes. Urol Clin North Am 46(2):147-163. https://doi.org/10.1016/j.ucl.2018.12.001 (PMID: 30961849)
4. Jones P, Beisland C, Ulvik Ø (2021) Current status of thulium fibre laser lithotripsy: an up-to-date review. BJU Int. https://doi. org/10.1111/bju.15551 (Epub ahead of print. PMID: 34273234)

5. Keller EX, de Coninck V, Audouin M, Doizi S, Bazin D, Daudon M, Traxer O (2019) Fragments and dust after Holmium laser lithotripsy with or without "Moses technology": how are they different? J Biophotonics 12(4):e201800227. https://doi.org/10. 1002/jbio.201800227 (Epub 2018 Dec 13 PMID: 30315636)

6. Mosquera L, Pietropaolo A, Madarriaga YQ et al (2021) Is flexible ureteroscopy and laser lithotripsy the new gold standard for pediatric lower pole stones? outcomes from two large European tertiary pediatric endourology centers. J Endourol 35(10):14791482. https://doi.org/10.1089/end.2020.1123 (PMID: 34006145)

7. Dasgupta R, Cameron S, Aucott L, MacLennan G, Thomas RE, Kilonzo MM, Lam TBL, N'Dow J, Norrie J, Anson K, Burgess N, Clark CT, Keeley FX Jr, MacLennan SJ, Starr K, McClinton S (2021) Shockwave lithotripsy versus ureteroscopic treatment as therapeutic interventions for stones of the ureter (TISU): a multicentre randomised controlled non-inferiority trial. Eur Urol 80(1):46-54. https://doi.org/10.1016/j.eururo.2021.02.044 (Epub 2021 Mar 31 PMID: 33810921; PMCID: PMC8234516)

8. Okada A, Yasui T, Taguchi K, Niimi K, Hirose Y, Hamamoto S, Ando R, Kubota Y, Umemoto Y, Tozawa K, Sasaki S, Hayashi Y, Kohri K (2013) Impact of official technical training for urologists on the efficacy of shock wave lithotripsy. Urolithiasis 41(6):487492. https://doi.org/10.1007/s00240-013-0586-3 (Epub 2013 Jul 3 PMID: 23821184)

9. Alexander CE, Gowland S, Cadwallader J, Reynard JM, Turney BW (2016) Shock wave lithotripsy (SWL): outcomes from a national SWL database in New Zealand. BJU Int 117(Suppl 4):76-81. https://doi.org/10.1111/bju.13431 (Epub 2016 Feb 29 PMID: 26923107)

10. Somani BK, Pietropaolo A, Coulter P et al (2020) Delivery of urological services (telemedicine and urgent surgery) during COVID-19 lockdown: experience and lessons learnt from a university hospital in United Kingdom. Scott Med J 65(4):109-111. https://doi.org/10.1177/0036933020951932 (Epub 2020 Aug 20 PMID: 32819219)

Publisher's Note Springer Nature remains neutral with regard to jurisdictional claims in published maps and institutional affiliations. 